\title{
Article
}

\section{A New Benzofuran Glucoside from Ficus Tikoua Bur}

\section{Shao-Peng Wei ${ }^{1,2,3}$, Jie-Yu Luan ${ }^{4}$, Li-Na Lu ${ }^{3}$, Wen-Jun Wu ${ }^{1,2,3}$ and Zhi-Qin Ji ${ }^{1,2,3, *}$}

1 State Key Laboratory of Crop Stress Biology in Arid Areas, Northwest A \& F University, Yangling 712100, Shaanxi, China; E-Mails: weishaopeng8888@163.com (S.-P.W.); wuwenjun@nwsuaf.edu.cn (W.-J.W.)

2 Key Laboratory of Plant Protection Resources and Pest Integrated Management, Ministry of Education, College of Plant Protection, Northwest A \& F University, Yangling 712100, Shaanxi, China

3 Shaanxi Province Key Laboratory Research \& Development on Botanical Pesticide, Northwest A \& F University, Yangling 712100, Shaanxi, China;

E-Mail: meiyadeselang@163.com

4 Xi'an Modern Chemistry Research Institute, Xi'an 710065, Shaanxi, China; E-Mail:wmc204@yahoo.com.cn

* Author to whom correspondence should be addressed; E-Mail: yljizhiqin@hotmail.com; Tel.: +86-29-87092191; Fax: +86-29-87093987.

Received: 11 July 2011; in revised form: 22 July 2011 / Accepted: 26 July 2011 /

Published: 3 August 2011

Abstract: From the water-soluble portion of the methanol extract of stems of Ficus tikoua Bur., a new benzofuran glucoside, named 6-carboxyethyl-5-hydroxybenzofuran 5-O- $\beta$-D-glucopyranoside (1), together with one known benzofuran glucoside (2) were isolated. Their structures were elucidated by $1 \mathrm{D}$ and $2 \mathrm{D}\left({ }^{1} \mathrm{H}-{ }^{1} \mathrm{H}\right.$ COSY, HMQC, and HMBC) NMR spectroscopy and HRMS techniques. The antioxidant activities of the isolated compounds were assayed based on the scavenging activities of DPPH free radical. Compounds $\mathbf{1}$ and $\mathbf{2}$ exhibited moderate antioxidant activities, and the $\mathrm{IC}_{50}$ values were $242.8 \mu \mathrm{g} \cdot \mathrm{mL}^{-1}$ and $324.9 \mu \mathrm{g} \cdot \mathrm{mL}^{-1}$, respectively.

Keywords: Ficus tikoua Bur.; benzofuran glucoside; antioxidant activity 


\section{Introduction}

Ficus tikoua Bur., a woody plant of Ficus genus, is widely distributed in south China, India, Vietam and Laos. It has long been used in traditional folk medicine to treat human diseases, such as chronic bronchitis, diarrhea, dysentery, mastadenitis, rheumatism, edema, impetigo, and so on [1,2]. The plants of Ficus genus have attracted considerable attention for pharmacologists due to a wide range of biological properties, including antioxidant [3-5], anti-inflammatory [6-8], cytotoxicity [9,10], antibacterial [6] and antifungal activities [11]. Previous studies show that the phenylpropanoids [12], flavonoids [11], coumarins [2], lignans [4], chromones [13], triterpenoids [14], sesquiterpenoids [15] and alkaloids [16] are the most widespread of the secondary metabolites isolated from the genus Ficus. However, only a few report about the chemical constituents of $F$. tikoua Bur. according to the published literature. As part of our ongoing search for novel secondary metabolites, the constituents of F. tikoua Bur. were investigated. This work has led to the isolation of a new (1) and one known (2) benzofuran glucoside from the water-soluble fraction of the methanol extract of $F$. tikoua Bur. (Figure 1). In this paper, the isolation, structure elucidation and the antioxidant activities of the isolates are presented.

Figure 1. Structures of benzofuran glucosides 1 and $\mathbf{2}$.
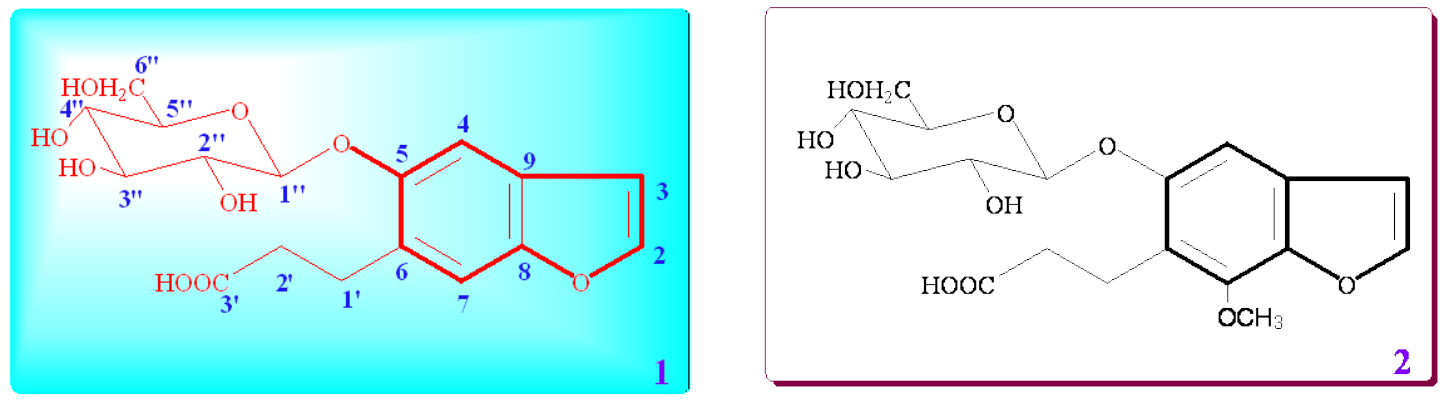

\section{Results and Discussion}

\subsection{Isolation and Identification}

Air-dried stem F. tikoua Bur. was extracted with methanol to obtain the crude extract. This residue was suspended in water and partitioned with ethyl acetate. The aqueous phases were subjected to column chromatography (macroporous and anion exchange resin) and reversed-phase HPLC to yield compounds 1 and 2. Their structures were elucidated on the basis of UV, ESI-MS/MS, HRMS and NMR spectroscopic data.

Compound $1\left(\mathrm{C}_{17} \mathrm{H}_{20} \mathrm{O}_{9}\right.$, an amorphous powder, $\left.[\alpha]_{\mathrm{D}}-29.0^{\circ}, \mathrm{MeOH}\right)$, had a molecular ion peak at $m / z$ 386.1449 $\left(\left[\mathrm{M}+\mathrm{NH}_{4}\right]^{+}\right.$, calcd. 386.1446) in HR-ESI-MS, in agreement with the molecular formula

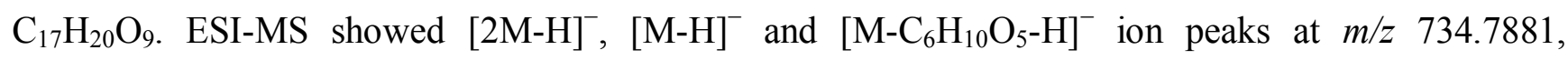
367.2128 and 205.1502 in the negative mode (Figure 2; Scheme 1). The acid hydrolysis of 1 gave D-glucose as a sugar component. The ${ }^{1} \mathrm{H}-,{ }^{13} \mathrm{C}$ - and ${ }^{13} \mathrm{C}-{ }^{1} \mathrm{H}$ correlation spectroscopy (COSY) NMR spectral revealed the presence of one tetrasubstituted benzene, one disubstituted double bond, one carboxyethyl and one $\beta$-glucopyranosyl unit in $\mathbf{1}$ (Table 1). The $\beta$-configuration of the anomeric center of glucopyranosyl was suggested by the large coupling constant $(J=7.5 \mathrm{~Hz})$. Comparison of its NMR 
data with Glycoside $8[17,18]$, which was isolated from the fruit of Glehnia littoralis, suggested that 1 also is a glucopyranoside of a benzofuran derivative and might be the regioisomer of the cnidioside A. This assumption was supported by a heteronuclear multiple-bond correlation (HMBC) experiment. The analysis of HMBC spectral and ${ }^{1} \mathrm{H}-{ }^{1} \mathrm{H}$ COSY spectral data (Figure 3) suggested a carboxyethyl group at C-6. The position of attachment of the glucosyl unit was revealed to be $\mathrm{C}-5$ from the $\mathrm{H}-\mathrm{C}$ long-range correlation between the glucosyl anomeric proton signal and the C-5 carbon in the HMBC spectrum. Therefore, 1 was characterized as 6-carboxyethyl-5-hydroxy-benzofuran 5-O- $\beta$-D-glucopyranoside.

Figure 2. ESI-MS (A) and ESI-MS ${ }^{\mathrm{n}}(\mathbf{B})$ for compound $\mathbf{1}$ in negative mode.

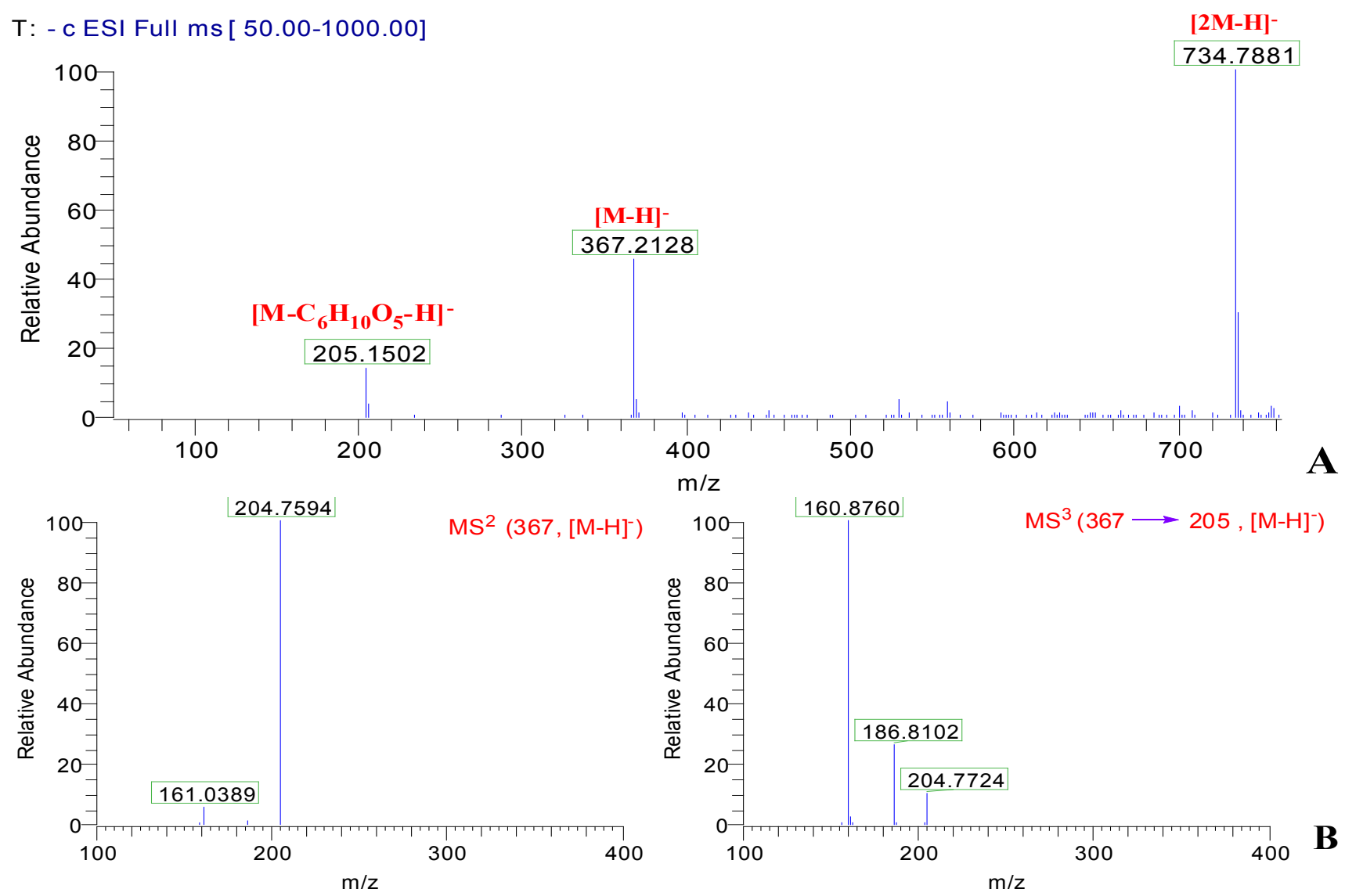

Scheme 1. Proposed fragmentation pathways of compound $\mathbf{1 .}$

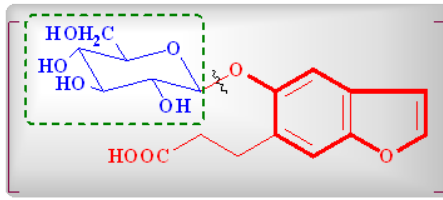

$m / z \quad 367$

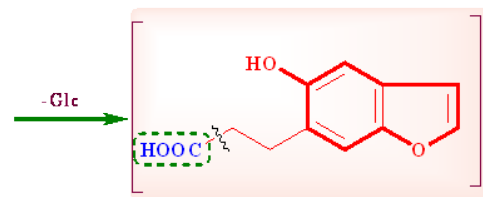

$m / 2205$
$-\mathrm{CO}_{2}$

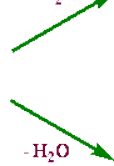

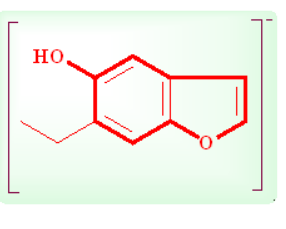

$m / z 161$

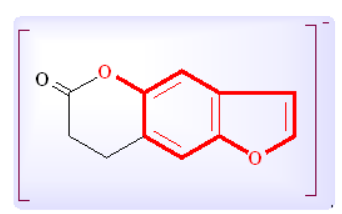

$m / z 187$ 
Table 1. The ${ }^{1} \mathrm{H}$ and ${ }^{13} \mathrm{C}-\mathrm{NMR}$ chemical shifts of compound $\mathbf{1}\left(\mathrm{D}_{2} \mathrm{O}, 500 \mathrm{MHz}\right)$.

\begin{tabular}{|c|c|c|c|c|}
\hline \multirow{2}{*}{ No. } & \multicolumn{2}{|r|}{1} & \multicolumn{2}{|r|}{2} \\
\hline & $\delta_{\mathrm{C}}$ & $\delta_{\mathrm{H}}(J / \mathrm{Hz})$ & $\delta_{\mathrm{C}}$ & $\delta_{\mathrm{H}}(J / \mathrm{Hz})$ \\
\hline $\mathrm{C}-2$ & $145.91 \mathrm{~d}$ & $7.61 \mathrm{~d}(2.0)$ & $144.65 \mathrm{~d}$ & $7.78 \mathrm{~d}(2.0)$ \\
\hline $\mathrm{C}-3$ & $107.15 \mathrm{~d}$ & $6.70 \mathrm{~d}(2.0)$ & $104.53 \mathrm{~d}$ & $7.10 \mathrm{~d}(2.0)$ \\
\hline$C-4$ & $99.77 \mathrm{~s}$ & $7.34 \mathrm{~s}$ & $94.33 \mathrm{~s}$ & $7.26 \mathrm{~s}$ \\
\hline $\mathrm{C}-5$ & $155.01 \mathrm{~s}$ & & $153.45 \mathrm{~s}$ & \\
\hline C-6 & $127.66 \mathrm{~s}$ & & $116.15 \mathrm{~s}$ & \\
\hline C-7 & $122.13 \mathrm{~s}$ & $7.37 \mathrm{~s}$ & $150.83 \mathrm{~s}$ & \\
\hline $\mathrm{C}-7(\mathrm{OMe})$ & & & $60.93 \mathrm{q}$ & $4.16 \mathrm{~s}$ \\
\hline C-8 & $155.80 \mathrm{~s}$ & & $155.19 \mathrm{~s}$ & \\
\hline C-9 & $123.23 \mathrm{~s}$ & & $113.75 \mathrm{~s}$ & \\
\hline $\mathrm{C}-1$, & $27.75 \mathrm{~m}$ & $2.99 \sim 3.08 \mathrm{~m}$ & $19.46 \mathrm{t}$ & $3.18 \mathrm{t}(7.5)$ \\
\hline C-2' & $36.61 \mathrm{~m}$ & $2.61 \sim 2.64 \mathrm{~m}$ & $34.70 \mathrm{t}$ & $2.71 \mathrm{t}(7.5)$ \\
\hline $\mathrm{C}-3^{\prime}$ & $178.84 \mathrm{~s}$ & & $178.87 \mathrm{~s}$ & \\
\hline \multicolumn{5}{|l|}{ Glc } \\
\hline $1 "$ & $103.22 \mathrm{~d}$ & $4.93 \mathrm{~d}(7.5)$ & $101.26 \mathrm{~d}$ & $5.20 \mathrm{~d}(7.5)$ \\
\hline $2 "$ & $75.00 \mathrm{~d}$ & $3.69 \mathrm{~m}$ & $73.29 \mathrm{~d}$ & $3.89 \mathrm{~m}$ \\
\hline $3 "$ & $78.18 \mathrm{~d}$ & $3.62 \mathrm{~m}$ & $76.10 \mathrm{~d}$ & $3.78 \mathrm{~m}$ \\
\hline $4 "$ & $71.40 \mathrm{~d}$ & $3.70 \mathrm{~m}$ & $69.75 \mathrm{~d}$ & $3.76 \mathrm{~m}$ \\
\hline $5 "$ & $78.18 \mathrm{~d}$ & $3.29 \mathrm{~m}$ & $76.37 \mathrm{~d}$ & $3.39 \mathrm{~m}$ \\
\hline $6 "$ & $62.56 \mathrm{t}$ & $3.80,4.02 \mathrm{~m}$ & $60.72 \mathrm{t}$ & $3.67,4.08 \mathrm{~m}$ \\
\hline
\end{tabular}

Figure 3. Key HMBC correlations for compound 1.

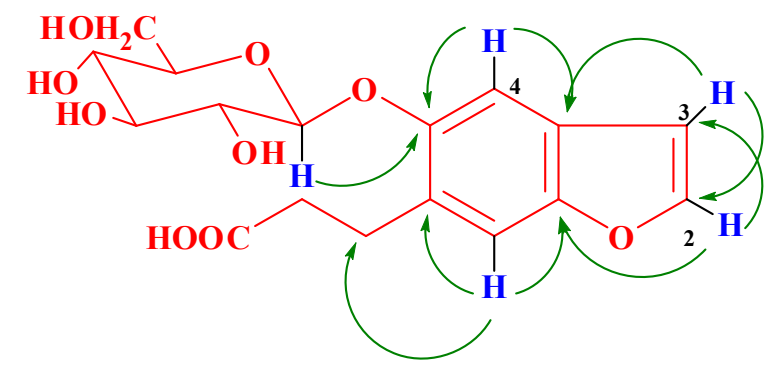

Compound $2\left(\mathrm{C}_{18} \mathrm{H}_{22} \mathrm{O}_{10}\right)$ was identified as 6-carboxyethyl-7-methoxyl-5-hydroxy-benzofuran 5-O- $\beta$-D-glucopyranoside based on UV, ESI-MS, ${ }^{1} \mathrm{H}$ - and ${ }^{13} \mathrm{C}-\mathrm{NMR}$ spectroscopic data (Table 1) [17].

\subsection{Antioxidant Activity}

Further, to assess the possible utilization of isolated compounds, the antioxidant activities were evaluated. DPPH is widely used to evaluate antioxidant capacity and changes color from purple to yellow upon acceptance of electrons/hydrogens, thus indicating scavenging activity. It was observed that compounds 1 and $\mathbf{2}$ moderately transformed the DPPH radical into its reduced form, and the $\mathrm{IC}_{50}$ values were 242.8 and $324.9 \mu \mathrm{g} \cdot \mathrm{mL}^{-1}$, respectively. It was very interesting to note that 2 exhibited weaker activities than $\mathbf{1}$, suggesting that the methoxy at $C_{7}$ might has a negative influence on antioxidant activity. 


\section{Experimental Section}

\subsection{General}

Solvents were of analytical reagent (AR) grade unless otherwise mentioned. Flash column chromatography (FC): $\mathrm{C}_{18}$ silica gel (particle size $15 \mu \mathrm{m}$; Fuji Silysia Chemical Ltd.). HPLC: Shimadzu-6AD HPLC apparatus; Hypersil $\mathrm{ODS}_{2}$ column $(250 \times 4.6 \mathrm{~mm} ; 5 \mu \mathrm{m})$ and $(250 \times 20 \mathrm{~mm}$; $10 \mu \mathrm{m}), \mathrm{MeOH}: \mathrm{H}_{2} \mathrm{O}=2: 8$ as eluent; $\mathrm{UV}$ detector at $230 \mathrm{~nm}$. Specific rotations, Perkin-Elmer 341 polarimeter; ${ }^{1} \mathrm{H}$ and ${ }^{13} \mathrm{C}-\mathrm{NMR}$ Spectra: Bruker-Avance-500 spectrometer; $\mathrm{MeOD}$ as solvent. HR-ESI-MS: Bruker Apex II mass spectrometer; ESI-MS: Thermo Finnigan LCQ Advantage MAX LC/MS mass spectrometer (USA); molecular scan range 100-1000 amu.

\subsection{Plant Material}

The stem of F. tikoua Bur. was collected in Hongya County, Sichuan Province, P.R. China, in September 2009, and authenticated by Prof. Hua Yi (College of Life Sciences, Northwest Agricultural and Forestry University). The voucher specimens (samples No. NWAU2009-FT15) were deposited with the College of Life Sciences, Northwest Agricultural and Forestry University.

\subsection{Extraction and Isolation}

The dried and pulverized stem $(5.0 \mathrm{~kg})$ of $F$. tikoua Bur. was extracted with methanol $(10 \mathrm{~L} \times 6)$ under reflux for $4 \mathrm{~h}$. The solvent was evaporated under reduced pressure to give a residue $(280.0 \mathrm{~g})$, equivalent to $5.6 \%$ of the weight of the dried sample. This residue was suspended in water $(5 \mathrm{~L})$ and partitioned with ethyl acetate $(5 \mathrm{~L} \times 3)$. The aqueous phase was subjected to column chromatography $(12.0 \times 150 \mathrm{~cm})$ packed with $2.0 \mathrm{~kg}$ D101 macroporous resin and gradiently eluted with mixed $\mathrm{H}_{2} \mathrm{O}$ and $\mathrm{MeOH}$ (100:0, 80:20, 60:40, 40:60, 20:80 and 0:100; $6 \mathrm{~L}$ of eluent for each step), 72 fractions of ca. $500 \mathrm{~mL}$ each which were combined to 6 fractions (HPLC monitoring). Then Fraction 2 was successively loaded on anion exchange resin column chromatography $(5.5 \times 100 \mathrm{~cm}$, eluted with $2 \%$ $\mathrm{HCl})$, reversed-phase flash column $\left(\mathrm{C}_{18}, \mathrm{MeOH}: \mathrm{H}_{2} \mathrm{O}\right)$. In this way, after column chromatography (macroporous and anion exchange resin), reversed-phase flash column and pre-HPLC, a new benzofuran glucoside $(1,48 \mathrm{mg})$ and 6-carboxyethyl-7-methoxy-5-hydroxybenzofuran-5-O- $\beta$-D-glucopyranoside $(2,103 \mathrm{mg})$ were isolated.

\subsection{Antioxidant Assays}

Antioxidant potential of compounds $\mathbf{1}$ and $\mathbf{2}$ were determined by a modification of the 1,1-diphenyl2-picrylhydrazyl (DPPH) radical scavenging method. Free radical scavenging activity of the tested sample against stable DPPH was determined spectrophotometrically by the slightly modified method of Gyamfi [19]. When DPPH reacts with an antioxidant, which can donate hydrogen, it is reduced. The changes in color (from deep-violet to light-yellow) were measured at $517 \mathrm{~nm}$ on a UV/vis light spectrophotometer. Fifty microliters of methanol solution of $\mathbf{1}$ and $\mathbf{2}$ at concentrations of $0.1,0.2,0.5$, 1 , and $2 \mathrm{mg} \cdot \mathrm{ml}^{-1}$, respectively, in each reaction was mixed with $1 \mathrm{~mL}$ of $0.1 \mathrm{mM} \mathrm{DPPH}$ in methanol solution and $450 \mu \mathrm{L}$ of $50 \mathrm{mM}$ Tris- $\mathrm{HCl}$ buffer $(\mathrm{pH}$ 7.4). After $30 \mathrm{~min}$ of incubation at room 
temperature the reduction of the DPPH free radical was measured spectrophotometrically. Methanol and tert-butyl hydroquinone (TBHQ) were used as negative and positive control, and all tests were carried out in triplicate. $\mathrm{IC}_{50}$ values (concentration of sample required to scavenge $50 \%$ of free radicals) were calculated from the regression equation, prepared from the concentration of the tested sample. Percentage inhibition of free radical formation/percentage inhibition DPPH was calculated from the following equation:

$$
\text { Inhibition } \%=\frac{\text { Absorbance of control }- \text { Absorbance of test sample }}{\text { Absorbance of control }} \times 100
$$

The data were statistically analyzed by using Student's $t$-test and analysis of variance for individual parameters was performed by Duncan's test on the basis of mean values to find out the significance at $p<0.05$. Correlation between antioxidant activities were carried out using the correlation and regression in the EXEL program.

\section{Conclusions}

A new benzofuran glucoside (6-carboxyethyl-5-hydroxybenzofuran 5-O- $\beta$-D-glucopyranoside), together with one known benzofuran glucoside (6-carboxyethyl-7-methoxyl-5-hydroxy-benzofuran 5 -O- $\beta$-D-glucopyranoside) were isolated from the water-soluble portion of Ficus tikoua Bur. The $\mathrm{IC}_{50}$ values were $242.8 \mu \mathrm{g} \cdot \mathrm{mL}^{-1}$ and $324.9 \mu \mathrm{g} \cdot \mathrm{mL}^{-1}$, based on the scavenging activities of DPPH free radical, respectively. It is suggested that Ficus tikoua could be considered as a source of antioxidant agent which might be applied in pharmaceutical and cosmetic products.

\section{Acknowledgments}

This work was supported by the National Key S\&T Research Foundation of China (2010CB126105), the National Natural Science Foundation of China (30871663) and the China Postdoctoral Science Foundation (Project No. 20100471644).

\section{References}

1. Guan, Y.X.; Yang, X.S.; Tong, L.H.; Yang, B.; Hao, X.J. Chemical constituents in Ficus tikoua of Miao nationality. Chin. Tradit. Herb. Drugs 2007, 38, 342-344.

2. Ahmed, F.; Urooj, A. Traditional uses, medicinal properties, and phytopharmacology of Ficus racemosa: A review. Pharm. Biol. 2010, 48, 672-681.

3. Chen, L.W.; Cheng, M.J.; Peng, C.F.; Chen, L.S. Secondary metabolites and anti-mycobacterial activities from the roots of Ficus nervosa. Chem. Biodivers. 2010, 7, 1814-1821.

4. Taiwo, B.J.; Aderogba, M.A.; Ogundaini, A.O. Antioxidant lignans from the leaves of Ficus exasperata. Niger. J. Nat. Prod. Med. 2006, 10, 111-113.

5. Donfack, J.H.; Simo, C.C.F.; Ngameni, B.; Tchana, A.N.; Kerr, P.G.; Finzi, P.V.; Vidari, G.; Giardina, S.; Buonocore, D.; Ngadjui, B.T.; et al. Antihepatotoxic and antioxidant activities of methanol extract and isolated compounds from Ficus chlamydocarpa. Nat. Prod. Commun. 2010, $5,1607-1612$. 
6. Muanda, N.F.; Dicko, A.; Soulimani, R. Chemical composition and biological activities of Ficus capensis leave extracts. J. Nat. Prod. (Gorakhpur, India) 2010, 3, 147-160.

7. Thakare, V.N.; Suralkar, A.A.; Deshpande, A.D.; Naik, S.R. Stem bark extraction of Ficus bengalensis Linn for anti-inflammatory and analgesic activity in animal models. Indian J. Exp. Biol. 2010, 48, 39-45.

8. Park, E.H.; Kahng, J.H.; Lee, S.H.; Shin, K.H. An anti-inflammatory principle from cactus. Fitoterapia 2001, 72, 288-290.

9. Chiang, Y.M.; Chang, J.Y.; Kuo, C.C.; Chang, C.Y.; Kuo, Y.H. Cytotoxic triterpenes from the aerial roots of Ficus microcarpa. Phytochemistry 2005, 66, 495-501.

10. Damu, A.G.; Kuo, P.C.; Shi, L.S.; Li, C.Y.; Su, C.R.; Wu, T.S. Cytotoxic phenanthroin-dolizidine alkaloids from the roots of Ficus septica. Planta Med. 2009, 75, 1152-1156.

11. Wang, X.G.; Wei, X.Y.; Tian, Y.Q.; Shen, L.T.; Xu, H.H. Antifungal flavonoids from Ficus sarmentosa var. henryi (King) Corner. Agric. Sci. China 2010, 9, 690-694.

12. Ouyang, M.A.; Chen, P.Q.; Wang, S.B. Water-soluble phenylpropanoid constituents from aerial roots of Ficus microcarpa. Nat. Prod. Res. 2007, 21, 769-774.

13. Basudan, O.A.; Ilyas, M.; Parveen, M.; Muhisen, H.M.H.; Kumar, P. A new chromone from Ficus lyrata. J. Asian Nat. Prod. Res. 2005, 7, 81-85.

14. Parveen, M.; Ghalib, R.M.; Mehdi, S.H.; Rehman, S.Z.; Ali, M. A new triterpenoid from the leaves of Ficus benjamina (var. comosa). Nat. Prod. Res., Part B 2009, 23, 729-736.

15. Kitajima, J.; Kimizuka, K.; Tanaka, Y. Three new sesquiterpenoid glucosides of Ficus pumila fruit. Chem. Pharm. Bull. 2000, 48, 77-80.

16. Ueda, J.Y.; Takagi, M.; Shin, Y.K. Aminocaprophenone and pyrrolidine-type alkaloids from the Leaves of Ficus septica. J. Nat. Prod. 2009, 72, 2181-2183.

17. Toru, I.; Yukiko, S.; Junichi, K. Water-soluble constituents of Glehnia littoralis fruit. Chem. Pharm. Bull. 2001, 49, 584-588.

18. Wang, M.A.; Peng, S.L.; Wang, M.K.; Lu, F.Q.; Ding, L.S. The Chemical Constituents from Aerial Parts of Chuanminshen Violaceum. Chem. J. Chin. Univ. 2002, 23, 1539-1542.

19. Gyamfi, M.A.; Yonamine, M.; Aniya, Y. Free-radical scavenging action of medicinal herbs from Ghana: Thonningia sanguinea on experimentally-induced liver injuries. Gen. Pharmacol. 1999, $32,661-667$.

(C) 2011 by the authors; licensee MDPI, Basel, Switzerland. This article is an open access article distributed under the terms and conditions of the Creative Commons Attribution license (http://creativecommons.org/licenses/by/3.0/). 